\title{
Readability, Presentation and Quality of Allergy-related Patient Information Leaflets; A Cross Sectional and Longitudinal Study
}

Priyamvada Paudyal ${ }^{1}$, Gabriella M Capel-Williams ${ }^{1}$, Elizabeth Griffiths ${ }^{1}$, Alice Theadom ${ }^{2}$, Anthony J Frew ${ }^{3}$ and Helen E Smith ${ }^{1}$

${ }^{1}$ Division of Primary Care and Public Health, Brighton and Sussex Medical School, Brighton, UK

${ }^{2}$ National Institute for Stroke and Applied Neuroscience, Person Centred Research Centre, Auckland University of Technology, Auckland, New Zealand

${ }^{3}$ Department of Respiratory Medicine, Royal Sussex County Hospital, Brighton, UK

"Corresponding author: Paudyal P, Division of Primary Care and Public Health, Brighton and Sussex Medical School, Brighton BN1 9PH, United Kingdom, Tel: +44 (0)1273644548, Fax: +44 (0) 1273 644440, E-mail: p.paudyal@bsms.ac.uk

Received date: March 18, 2015; Accepted date: June 26, 2015; Published date: July 02, 2015

Copyright: (C) 2015 Paudyal P, et al. This is an open-access article distributed under the terms of the Creative Commons Attribution License, which permits unrestricted use, distribution, and reproduction in any medium, provided the original author and source are credited.

\begin{abstract}
Objective:Patient information leaflets (PILs) are widely used to reinforce or illustrate health information and to complement verbal consultation. The objectives of the study were to assess the readability and presentation of PILs published by Allergy UK, and to conduct a longitudinal assessment to evaluate the impact of leaflet amendment and revision on readability.

Methods:Readability of Allergy UK leaflets available in 2013 was assessed using Simple Measure of Gobbledegook (SMOG) and Flesch-Kincaid Reading Grade Formula. Leaflet presentation was evaluated using the Clear Print Guidelines of the Royal National Institute of Blind People (RNIB) and the Patient Information Appraisal System developed by the British Medical Association (BMA). Changes in the leaflets' readability scores over five years were investigated.
\end{abstract}

Results:108 leaflets, covering a wide range of allergic conditions and treatment options, were assessed. The leaflets had average SMOG and Flesch-Kincaid scores of 13.9 (range 11-18, SD 1.2) and 10.9 (range 5-17, SD 2.1) respectively. All leaflets met the RNIB Clear Print guidelines, with the exception of font size which was universally inadequate. The leaflets scored on average 10 (median 10, range 7-15) out of a maximum of 27 on the BMA checklist. The overall average SMOG score of 31 leaflets available in both 2008 and 2013 had not changed significantly. The process of leaflet revision resulted in $1 \%$ change in readability scores overall, with a predominantly upward trend with six leaflets increasing their readability score by $>10 \%$ and only three decreasing by $>10 \%$.

Conclusion:Allergy-related patient information leaflets are well presented but have readability levels that are higher than those recommended for health information. Involving service users in the process of leaflet design, together with systematic pre-publication screening of readability would enhance the accessibility and comprehensibility of written information for people with allergy and their careers.

Keywords: Patient information leaflets; Allergy; Readability; Presentation; Quality

\section{Introduction}

Allergic disorders are common in the developed world. Approximately one in three people in the UK and one in five people in the USA suffer from allergic disease [1,2]. The management of allergies is primarily dependent on the patient being aware of the triggers and then reducing exposure to the relevant allergens. This requires the patient to have a clear understanding about their condition and how to manage their symptoms effectively. Information given verbally during a consultation can be quickly forgotten and is frequently misinterpreted [3]. Hence, patient information leaflets (PILS) are used to augment the advice offered during the clinical encounter [4], empowering patients to become more involved in their treatment decisions and to take greater self-care [5]. Good information leaflets have been found to be helpful in reducing anxiety about patients' illness or treatment [6], improving compliance or concordance with treatment [7], and contributing to improved illness outcomes.

The quality and usability of written materials for patients with atopic disorders are not always optimum [8,9]. Our previous review of 168 leaflets for people with asthma showed that 23\% contained inaccurate or misleading information and $97 \%$ of leaflets were written above the recommended reading level for health literature [10]. In another study exploring the readability of PILs about hay fever, leaflets were also found to be of variable quality as well as having readability scores making the information inaccessible to a substantial proportion of the patient population [11]. Similar problems with readability were also identified when reviewing a series of allergy-related leaflets published by the American Academy of Allergy, Asthma and Immunology [12].

It is important that information provided to patients is written at a level which ensures that it can be understood by most of the population. Improved readability has been found to be associated with better recall and comprehension of information [13]. Readability formulae can be used to assess health literature, and these are often 
preferred to reader review because of their speed and ease of use. There are several formulae in common use, including Flesch-Kincaid, Flesch Reading Ease, SMOG, Fry, Fog, and Dale-Chall. Each of these formulae use different mathematical equations to estimate the reading grade level required for the reader to understand the written information [14]. The characteristics of the written text used to calculate reading grade level vary between formulae. Some use average number of syllables in each word, others average number of words in a sentence, proportion of common words used, proportion of words with three or more syllables, or proportion of words which are monosyllabic [15]. Whilst readability formulae are now widely used in evaluation of written materials, they are not a panacea. They have been criticised for failing to acknowledge that the writing style, presentation format together with the prior knowledge and interests of the reader (such as familiarity with the terms associated with their own medical conditions) also impact on the readability of the text. To address these limitations of readability scores it is advisable to use alongside them measures which can assess the different facets of presentation and quality.

Allergy UK (originally formed in 1991 as the British Allergy Foundation, and re-launched as Allergy UK in 2002) is a charitable organization established to support and empower people with allergy, intolerance or sensitivities. The organization provides education and advice, publishing a large range of leaflets on allergy, intolerance and sensitivities for the public (www.allergyuk.org/info-factsheets.aspx). Allergy UK has been very proactive, constantly expanding its range of leaflets and revising and amending existing ones. This study thus aimed to assess the readability, presentation and quality of the leaflets published by Allergy UK and also investigates the changes in readability over time as the organization has refined their leaflets. We recognize that many studies have assessed the readability of PILs relating to a range of specific diseases or conditions, but we are not aware of any previous studies that have conducted a longitudinal assessment [16].

\section{Methods}

\section{Assessment of readability}

We evaluated readability of the leaflets using two scores, the Simple Measure of Gobbledegook (SMOG) and the Flesch-Kincaid Formula.

\section{SMOG}

The SMOG score [17] is calculated by taking 10 consecutive sentences from the beginning, middle and end of the text. The numbers of polysyllabic words within the 30 sentences are counted and the square root of this total is calculated. A constant of three is then added to yield the reading grade level of the text. For this study SMOG scores were calculated using an online software program developed by McLaughlin [18]. A SMOG score predicts the reading grade level needed to understand $100 \%$ of the text: the lower the reading grade level, the easier the information is to understand. Completed primary school education is needed for reading material with a SMOG score of 3-8, secondary school education is needed for SMOG score of 9-12, and tertiary education is needed for SMOG score of 13 and above [11]. It is recommended that health information should be written with a SMOG score of $\leq 5$ [19].

\section{Flesch-Kincaid}

The Flesch-Kincaid formula incorporates word and sentence length, and the average number of syllables. The formula utilized to calculate the score is $(0.39 \times$ Average sentence length $)+(11.8 \times$ Average syllables per word)-15.59 [20]. This formula result in a FleschKincaid score which corresponds to a school grade in an American school, for example, a score of 8.2 would mean that a student in the 8th grade in an American school would understand $75 \%$ or more of the passage. By adding five to the score, the equivalent age in years of the reader is obtained, for example 13 years in this case. The lower the grade level, the easier the information is to understand. For patient health information, it is recommended that readability Flesch-Kincaid Grade scores should be between 4-6 [21]. The Flesch-Kincaid score for the Allergy UK leaflets was calculated using the readability statistics application in Microsoft Word 2010.

In January 2013, we reviewed all the Allergy UK leaflets available at that time. By using a methodology used in previous reviews of Allergy UK leaflets conducted in 2008, 2010 and 2012 we were able to investigate the changes in SMOG readability scores across five years for those 31 topics for which leaflets were available at each time point. As different researchers were involved in these different assessments we needed to confirm the inter and the intra reliability of the SMOG assessments. We tested for inter-rater reliability by randomly selecting 10 leaflets and asking three raters (HS, GC, and PP) to score them. To evaluate intra-rater reliability, one rater (GC), assessed the same leaflets on two separate occasions. Intraclass correlation coefficients (ICC), together with $95 \%$ confidence intervals, were calculated using SPSS (SPSS, Inc., Chicago, Ill) statistical software. ICC values of $<0.4$ were deemed as representing poor reliability, $0.4-0.75$ as fair to good reliability, and $>0.75$ as excellent reliability [22].

\section{Assessment of presentation and quality}

The quality and presentation of the leaflets were evaluated based on the Clear Print Guidelines of the Royal National Institute of Blind People (RNIB) [23] and the patient information appraisal system developed by the British Medical Association (BMA) [24]. The RNIB guidelines were created to facilitate the design of documents that are easy to read, enabling essential information to be clearly conveyed to readers. The check list includes 15 items (e.g. "simple and clear typeface used", "text is left aligned") and each leaflet is scored against each criteria as "yes," "no," "don't know" or "not applicable (n/a)". The BMA patient information appraisal system includes 27 items worded as questions (e.g. "is the target readership clearly stated?") Twenty six items focus on quality and content, and one item on leaflet presentation (Table 1). Each item is judged "yes" (scored as 1 point), "no" or "do not know" (scored as 0 points). The total score for each leaflet was calculated together with the proportion of leaflets meeting individual criteria.

\section{Results}

In January 2013, 108 leaflets for adults were available on the Allergy UK website. The leaflets addressed allergy-related conditions (e.g. anaphylaxis, asthma, urticaria and angioedema), specific allergens (e.g. latex, egg, and nickel), diagnostic procedures and treatment options (e.g. immunotherapy, complementary and alternative therapies). Other leaflets focused on specific situations when self-care may be challenging (e.g. holidays, food shopping). A list of all the leaflets can be found in Appendices A and B. 
Citation: Paudyal P, Capel-Williams G M, Griffiths E, Theadom A, Frew A J, et. al (2015) Readability, Presentation and Quality of Allergy-related Patient Information Leaflets; A Cross Sectional and Longitudinal Study. J Allergy Ther 6: 213. doi:10.4172/2155-6121.1000213

Page 3 of 7

\begin{tabular}{|c|c|c|c|c|c|}
\hline Leaflet topic & 2008 & 2010 & 2012 & 2013 & $\begin{array}{l}\% \text { change } \\
2008-2013\end{array}$ \\
\hline Allergen Avoidance & 11.72 & 11.65 & 14 & $14.26^{\mathrm{a}}$ & $21.7^{\mathrm{b}}$ \\
\hline Allergy medications & 12.05 & 13.09 & 12.22 & $13.35^{\mathrm{a}}$ & $10.8^{\mathrm{b}}$ \\
\hline Allergy to cosmetics & 14.17 & 15.08 & 15.07 & 13.61 & -4 \\
\hline Allergy to domestic pets & 13.25 & 13.38 & 14.12 & 12.55 & -5.3 \\
\hline Anaphylaxis and severe allergic reaction & 14.34 & 15.35 & 12.97 & $14.43^{\mathrm{a}}$ & 0.6 \\
\hline Asthma & 11.31 & 12.94 & 12.16 & $12.77^{\mathrm{a}}$ & $12.9^{\mathrm{b}}$ \\
\hline Atopic eczema & 15.17 & 16.51 & 15.62 & 14.87 & -2 \\
\hline Catering guide to severe food allergies & 10.78 & 11.41 & 12.11 & $15.46^{\mathrm{a}}$ & $43.4^{\mathrm{b}}$ \\
\hline Complementary and alternative medicine & 16.19 & 18.68 & 18.53 & 15.13 & -6.5 \\
\hline Diagnosis of allergy in children & 14.62 & 14.48 & 13.55 & 13.55 & -7.3 \\
\hline Egg allergy & 13.27 & 16.04 & 12.45 & 12.88 & -2.9 \\
\hline First aid anaphylaxis & 15.17 & 14.41 & 14.84 & $15.53^{a}$ & 2.4 \\
\hline Fish and sea food allergy & 15.67 & 16.61 & 16.44 & 13.55 & $-13.5^{c}$ \\
\hline Food allergy in children & 14.81 & 15.7 & 15.29 & 13.25 & $-10.5^{c}$ \\
\hline Hay fever and allergic rhinitis & 13.43 & 12.79 & 13.02 & $13.81^{\mathrm{a}}$ & 2.8 \\
\hline Immunotherapy & 13.16 & 13.52 & 15.11 & $14.49^{a}$ & $10.1^{\mathrm{b}}$ \\
\hline Milk allergy & 13.41 & 15.5 & 12.97 & 12.35 & -7.9 \\
\hline Mould allergy advice & 11.77 & 10.65 & 12.65 & 11.17 & -5.1 \\
\hline Nickel allergy & 11.74 & 11.8 & 11.74 & $13.1^{\mathrm{a}}$ & $11.6^{\mathrm{b}}$ \\
\hline Oral allergy syndrome & 12.49 & 15.75 & 12.57 & $12.67^{\mathrm{a}}$ & 1.4 \\
\hline Peanut and tree nut allergy & 12.85 & 15.75 & 14.22 & 12.11 & -5.8 \\
\hline Pollen and moulds in the garden & 11.49 & 12.7 & 11.34 & $11.45^{\mathrm{a}}$ & -0.3 \\
\hline Rubber latex allergy & 13.76 & 13.87 & 14.2 & $13.82^{\mathrm{a}}$ & 0.4 \\
\hline Salicylate and aspirin & 12.56 & 12.97 & 11.86 & $14.07^{\mathrm{a}}$ & 12 \\
\hline Sesame and other seeds allergy & 14.35 & 14.73 & 15.69 & 13.12 & -8.6 \\
\hline Shopping and cooking for a restricted diet & 12.75 & 15.6 & 13.9 & $13.14^{\mathrm{a}}$ & 3.1 \\
\hline Soya (soy) allergy & 15.08 & 15.97 & 13.02 & $15.2^{\mathrm{a}}$ & 0.8 \\
\hline Sun sensitivity & 13.17 & 14.18 & 13.73 & $14.24^{a}$ & 8.1 \\
\hline Travelling with food allergy & 11.55 & 12.81 & 11.98 & $12.06^{a}$ & 4.4 \\
\hline Urticaria and angioedema & 14.62 & 14.69 & 13.61 & 13.16 & $-10^{c}$ \\
\hline Wasp and bee sting allergy & 13.9 & 14.52 & 12.4 & 13.73 & -1.2 \\
\hline Average SMOG score & 13.37 & 14.29 & 13.66 & 13.51 & 1 \\
\hline \multicolumn{6}{|l|}{ a2013 SMOG score higher than 2012 score } \\
\hline
\end{tabular}


Citation: Paudyal P, Capel-Williams G M, Griffiths E, Theadom A, Frew A J, et. al (2015) Readability, Presentation and Quality of Allergy-related Patient Information Leaflets; A Cross Sectional and Longitudinal Study. J Allergy Ther 6: 213. doi:10.4172/2155-6121.1000213

Page 4 of 7

c\% change between 2008 to $2013 \leq 10 \%$

Table 1: SMOG score values of Allergy UK leaflets from 2008, 2010, 2012 and 2013.

\section{Readability analysis}

The SMOG scores of the leaflets ranged from 11 to 18 (median 14 , mean 13.9, SD 1.2) (Table 2). No leaflets met the recommended SMOG score for health literature of five or below, eleven leaflets (10\%) were at a reading level comparable with successful completion of secondary education and the majority $(90 \%)$ required reading skills equivalent to a university level education. Flesch-Kincaid scores ranged from 5 to 17 (median 11, mean 10.86, SD 2.1). Six leaflets met the recommended level for patient health information (i.e. between 4-6).

\begin{tabular}{|c|c|c|}
\hline Readability score & No of Leaflets (\%) & Cumulative \% \\
\hline \multicolumn{3}{|l|}{$\mathrm{SMOG}^{*}$} \\
\hline 11 & $2(2)$ & 2 \\
\hline 12 & $9(8)$ & 10 \\
\hline 13 & $32(30)$ & 40 \\
\hline 14 & $42(39)$ & 79 \\
\hline 15 & $14(13)$ & 92 \\
\hline 16 & $4(4)$ & 96 \\
\hline 17 & $3(3)$ & 98 \\
\hline 18 & $2(2)$ & 100 \\
\hline \multicolumn{3}{|l|}{ Flesch-Kincaid $^{* *}$} \\
\hline 5 & $1(1)$ & 1 \\
\hline 6 & $5(5)$ & 6 \\
\hline 7 & $5(5)$ & 11 \\
\hline 8 & $4(4)$ & 15 \\
\hline 9 & $8(7)$ & 21 \\
\hline 10 & $10(9)$ & 30 \\
\hline 11 & $28(26)$ & 56 \\
\hline 12 & $31(29)$ & 85 \\
\hline 13 & $10(9)$ & 94 \\
\hline 14 & $3(3)$ & 97 \\
\hline 15 & $2(2)$ & 99 \\
\hline 16 & $0(0)$ & 99 \\
\hline 17 & $1(1)$ & 100 \\
\hline
\end{tabular}

Table 2: Readability scores of allergy UK leaflets.

\section{Assessment of presentation and quality}

All leaflets met the RNIB 'See it right' clear print guidelines relating to clear design and ease of reading with the exception of font size, all were published using font size of 11.5 rather than the recommended type size of 12 point or ideally 14 point.

The leaflets scored on average 10 (median 10, range 7-15) out of a maximum possible score of 27 on the BMA appraisal checklist for 
Page 5 of 7

quality, content and presentation (Figure 1). All the leaflets had professionals involved in their development and evaluation, and clearly stated the authors and agencies involved in production. The language and tone used in the leaflets was clear and appropriate, and information on the source organization was stated in all leaflets. The target readership was clearly stated in $88 \%$ of leaflets. As many of the leaflets followed a common design template there was considerable consistency in the design and quality features that were missing, for example none of the leaflets were specifically targeted at non-English speakers, or those with disabilities, specific cultures or religious beliefs. In the majority of leaflets (81\%), the scope and aims were not clearly stated, and in only approximately one third $(31 \%)$ were uncertainties and gaps in scientific knowledge addressed. In none was there a statement that patients or users had been involved in the development and evaluation of the leaflet. Less than half of leaflets (41\%) provided the reader with suggestions for further reading or useful addresses, and only $9 \%$ of the leaflets listed other leaflets published by Allergy UK. Only $19 \%$ of the leaflets contained a key points section (Table 3 ).

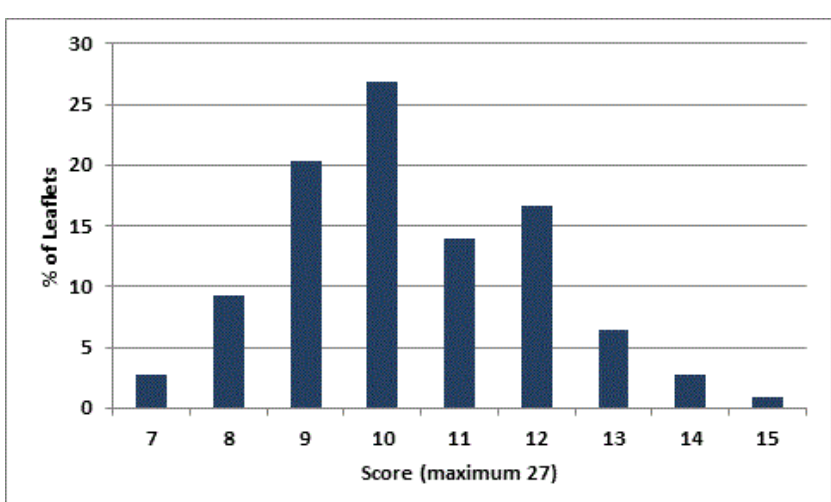

Figure 1: Distribution of BMA appraisal criteria scores for allergy UK leaflets $(n=108)$.

\section{Longitudinal analysis}

We were confident about comparing readability data across time as we demonstrated excellent intra- and inter-rater reliability for the SMOG score assessment (ICC $=0.997$ 95\% CI (0.989-0.999) and 0.996 (0.989-0.999) respectively).

There were 31 leaflets eligible for inclusion in the comparative analysis. A full list of these leaflets and their SMOG scores in 2008, 2010, 2012 and 2013 can be found in Table 2. The average SMOG score varied slightly between years (range 13.3 to 14.3), with the highest average score in 2010. The process of leaflet revision between 2008 and 2013 resulted $1 \%$ change in average readability score (mean readability score 13.37 vs $13.51 ; \mathrm{p}=0.58$ ). However, when considering the readability changes within individual leaflets there was a predominantly adverse trend, with six leaflets increasing their SMOG readability score by more than $10 \%$ and only three decreasing by less than $10 \%$.

\section{Discussion}

\section{Summary of key findings}

Our assessment of the readability and presentation of 108 leaflets published by Allergy UK in 2013 found that the leaflets were generally well presented according to the RNIB and BMA appraisal guidelines. Further modifications, such as increase in font size and the addition of a key point section, would improve the accessibility of information. Whilst presentation characteristics were moderately good, the readability levels of these leaflets was very high, often requiring a reading ability comparable with the successful completion of secondary education and in some cases a university degree. All the leaflets except six were still above the recommended reading grade level for health information and there had been no improvement in readability over five years of leaflet refinement and modification.

\section{Choosing between two readability scores}

In this study, the mean readability scores estimated using FleschKincaid were three grades lower than the SMOG score. Such variations in scores complicate the interpretation of reading grade data. In the absence of standardized ways for applying and interpreting readability formulas, some experts suggest choosing the highest calculated reading grade level estimate, others suggest calculating an average, whilst others recommend prevention of the dilemma by confining assessment to a single readability formula [14]. The Flesch-Kincaid formula expects lower comprehension compared to SMOG (75\% vs. $100 \%$ comprehension). For healthcare information it may be argued that close to $100 \%$ comprehension is needed and therefore the SMOG formula score is preferable to Flesch-Kincaid [14].

\section{Why does readability matter?}

Being attentive to readability of PILS is important given the prevalence of functional illiteracy in westernised countries: for example the National Literacy Trust estimates that in the UK one in six people have a reading ability less that that expected of an eleven year old, and therefore they struggle with literacy [25]. Our longitudinal assessment of readability of Allergy UK leaflets over five years shows that despite the strong commitment of the organization to improve their patient information there is a significant and sustained mismatch between the published material and the range of reading skills in the general public. Given the plethora of materials that exist on the writing and testing of user-friendly materials, one might wonder why organizations continue to publish leaflets that require relatively high reading skills that may not exist in a large proportion of their target population. A qualitative study in Israel explored the reasons behind this and highlighted some unexpected complexities of PIL development, including organizational politics and conflicting agendas [26]. The researchers found that PILS often emerged from an iterative and dynamic process that required resolution of opposing demands (e.g. existing materials versus suggestions from experts). They cited situations where experts insist on including additional technical detail in order to improve medical accuracy, to augment the perceived sophistication of the PIL or perhaps to improve medicolegal defensibility. It might be helpful for Allergy UK to undertake a broad ecological review of their process for creating and refining PILS and, having identified the intellectual, technical, organizational and political factors in play, to establish design procedures to prevent readability gaps. 
Citation: Paudyal P, Capel-Williams G M, Griffiths E, Theadom A, Frew A J, et. al (2015) Readability, Presentation and Quality of Allergy-related Patient Information Leaflets; A Cross Sectional and Longitudinal Study. J Allergy Ther 6: 213. doi:10.4172/2155-6121.1000213

Page 6 of 7

\section{The role of patients in PIL development}

None of the Allergy UK leaflets were explicit about whether patients had been involved in the development and evaluation process of these leaflets. The supply of useful information to patients is dependent on establishing what patients already know and what they want to know [26]. Clinicians often make erroneous judgements about what patients do or do not want to know or assume they already are in possession of the knowledge [27], thus leaving patients with an unfulfilled desire for knowledge. Working directly with patients to inform content may also generate patient anecdotes and case studies: this is beneficial as it is recognized that knowledge of others' experiences can facilitate compliance [26].

\begin{tabular}{|c|c|}
\hline BMA Appraisal Criteria & $\%$ of leaflets meeting criteria \\
\hline \multicolumn{2}{|l|}{ Criteria met universally } \\
\hline Are individual authors and agencies involved in its production clearly stated? & $100 \%$ \\
\hline Does the leaflet use clear appropriate language and tone? & $100 \%$ \\
\hline Does it include clear information on the source organization? & $100 \%$ \\
\hline Have professionals been involved in the development and evaluation of this resource? & $100 \%$ \\
\hline \multicolumn{2}{|l|}{ Criteria met partially } \\
\hline Does the leaflet clearly explain the condition or issues concerned? & $99 \%$ \\
\hline Is the leaflet well designed? (i.e. size, layout, use of colour, typeface) & $98 \%$ \\
\hline Is it clear when this leaflet was produced and if it updates a previous version? & $98 \%$ \\
\hline Is the target readership clearly stated? & $88 \%$ \\
\hline Does it provide unbiased information on outcomes based on recent research evidence? & $64 \%$ \\
\hline Is information provided on all available treatment options? & $48 \%$ \\
\hline Does it include suggestions for further reading and other useful addresses? & $41 \%$ \\
\hline Does it address uncertainties and gaps in scientific knowledge? & $31 \%$ \\
\hline Does it include a key points section? & $19 \%$ \\
\hline Are the scope and aims of the leaflet clearly stated? & $19 \%$ \\
\hline Are quality of life issues addressed? & $19 \%$ \\
\hline Are other leaflets in the series by the same organization listed? & $19 \%$ \\
\hline Does the leaflet include case studies and patient anecdotes & $13 \%$ \\
\hline Does it include referenced statements? & $3 \%$ \\
\hline \multicolumn{2}{|l|}{ Criteria met by none } \\
\hline Have users been involved in the development and evaluation of this resource? & $0 \%$ \\
\hline Does it cater for users such as non-English speakers and people with disabilities? & $0 \%$ \\
\hline Does it cater for users of different cultures and religious beliefs? & $0 \%$ \\
\hline Does the leaflet have a contents page? & $0 \%$ \\
\hline Does it provide a glossary of terms? & $0 \%$ \\
\hline Does it provide space for the user to record personal details or questions? & $0 \%$ \\
\hline Does it have a feedback form for user comments? & $0 \%$ \\
\hline Does it outline the NHS "journey" for the condition? & $0 \%$ \\
\hline Is the leaflet endorsed by a public figure? & $0 \%$ \\
\hline
\end{tabular}

Table 3: Percentage of leaflets meeting BMA appraisal criteria $(n=108)$. 
Citation: Paudyal P, Capel-Williams G M, Griffiths E, Theadom A, Frew A J, et. al (2015) Readability, Presentation and Quality of Allergy-related Patient Information Leaflets; A Cross Sectional and Longitudinal Study. J Allergy Ther 6: 213. doi:10.4172/2155-6121.1000213

Page 7 of 7

\section{Strengths and weaknesses}

Strength of this study is that it included two unusual features; a unique longitudinal assessment of readability scores across five years, and a formal assessment of the repeatability of SMOG score measurement. However, this study does have some potential weaknesses. Due to time constraints we did not assess the repeatability of all the measures used. As the BMA Appraisal guidelines are relatively subjective there is the potential for observer bias, but this risk could have been minimised by the use of more than one reviewer. A further methodological refinement would have been to re-evaluate the readability of the leaflets omitting common polysyllabic words associated with the illness and that would be very familiar to the reader, for example words such as allergy, anaphylaxis or urticaria. Removal from the text before scoring of complex, but frequently used, medical terminology has been associated with significant improvements in readability scores [28].

This study demonstrates that even when an organization has an active program of PIL revision readability does not automatically improve. A global review of the PIL writing procedure is needed to identify the drivers for change and resolve these issues that conflict with a need to increase readability. Other tactics include patient involvement in design, pre-publication screening of readability and post-production evaluation beyond just monitoring the number of leaflets requested. No PIL will ever meet every individual's needs but a better understanding of literacy in the target population can help maximize the benefit derived from the resource-intensive process of leaflet preparation.

\section{References}

1. Gupta R, Sheikh A, Strachan DP, Anderson HR (2007) Time trends in allergic disorders in the UK. Thorax 62: 91-96.

2. Allergy Facts and Figures. Asthma and Allergy Foundation of America.

3. Anderson J, Dodman S, Kopelman M, Fleming A (1979) Patient information recall in a rheumatology clinic. Rheumatology 18: 18-22.

4. Moerenhout T, Borgermans L, Schol S, Vansintejan J, Van De Vijver E, et al. (2013) Patient health information materials in waiting rooms of family physicians: do patients care? Patient preference and adherence 7: 489-497.

5. Pinnock H, Sheikh A (2004) Meeting the information needs of patients with allergic disorders: partnership is the key. Clinical \& Experimental Allergy 34: 1333-1335.

6. Jackson C, Lindsay S (1995) Reducing anxiety in new dental patients by means of leaflets. British dental journal 179: 163-167.

7. Arthur VA (1995) Written patient information: a review of the literature. JAdv Nurs. 21: 1081-1086.

8. Coulter A (1998) Evidence based patient information: Is important, so there needs to be a national strategy to ensure it. BMJ. 317: 225-226.

9. Fitzmaurice D, Adams J (2000) A systematic review of patient information leaflets for hypertension. Journal of human hypertension 14 : 259-262.
10. Smith H, Gooding S, Brown R, Frew A (1998) Evaluation of readability and accuracy of information leaflets in general practice for patients with asthma. Bmj 317: 264-265.

11. White P, Smith H, Webley F, Frew A (2004) A survey of the quality of information leaflets on hayfever available from general practices and community pharmacies. Clinical \& Experimental Allergy 34: 1438-1443.

12. Smith H, Wade J, Frew A (2008) How readable are the American Academy of Allergy, Asthma \& Immunology "Tips to Remember" leaflets? J Allergy Clin Immunol. 121: 770-773.

13. Hill J, Bird H (2003) The development and evaluation of a drug information leaflet for patients with rheumatoid arthritis. Rheumatology 42: 66-70.

14. Wang L-W, Miller MJ, Schmitt MR, Wen FK (2013) Assessing readability formula differences with written health information materials: application, results, and recommendations. Research in Social and Administrative Pharmacy 9: 503-516.

15. Ley P, Florio T (1996) The use of readability formulas in health care. Psychology, Health \& Medicine 1: 7-28.

16. Friedman DB, Hoffman-Goetz L (2006) A systematic review of readability and comprehension instruments used for print and webbased cancer information. Health Education \& Behavior 33: 352-373.

17. McLaughlin GH (1969) SMOG grading: A new readability formula. Journal of reading. 12: 639-646.

18. McLaughlin GH (2008) The Simple Measure of Gobbledegook (SMOG).

19. Estey A, Musseau A, Keehn L (1991) Comprehension levels of patients reading health information. Patient Education and Counseling 18: 165-169.

20. Kincaid JP, Fishburne Jr RP, Rogers RL, Chissom BS (1975) Derivation of new readability formulas (automated readability index, fog count and flesch reading ease formula) for navy enlisted personnel. DTIC Document.

21. Matthews TL, Sewell JC (2002) State official's guide to health literacy. Council of State Governments.

22. Fleiss JL (1986) Reliability of Measurement. In: The Design and Analysis of Clinical Experiments. John Wiley \& sons, pp. 1-32.

23. RNIB (2006) See it right: making information accessible for people with sight problems.

24. Duman M (2003) Producing Patient Information: How to research, develop and produce effective information resources. King's Fund, London.

25. Jama D, Dugdale G (2010) Literacy: State of the Nation: A picture of literacy in the UK today. National Literacy Trust.

26. Donovan JL, Blake DR (1992) Patient non-compliance: deviance or reasoned decision-making? Soc Sci Med. 34: 507-513.

27. Silvers IJ, Hovell MF, Weisman MH, Mueller MR (1985) Assessing physician/patient perceptions in rheumatoid arthritis. A vital component in patient education. Arthritis \& Rheumatism 28: 300-307.

28. Sand-Jecklin K (2007) The impact of medical terminology on readability of patient education materials. Journal of community health nursing 24 : 119-129. 